\title{
UN BICENTENARIO DE ESCLAVITUD FEMENINA: \\ ANÁLISIS DE 200 AÑOS DE EVOLUCIÓN JURÍDICO-PENAL EN HONDURAS
}

\author{
A BICENTENNIAL OF FEMALE SLAVERY: \\ ANALYSIS OF 200 YEARS OF LEGAL-CRIMINAL EVOLUTION IN HONDURAS
}

G. Larissa Reyes Vásquez ${ }^{1}$

DOI: https://doi.org/10.5377//rd.v42i1.12929

\section{RESUMEN:}

La explotación humana ha acompañado la evolución de la humanidad misma a través del tiempo. A pesar de ser una práctica abolida y prohibida a todos los niveles, en realidad ha sido capaz de adaptarse a cada época, incluso en Honduras. Por esa razón, bajo una óptica jurídica, el presente trabajo de investigación resume y analiza el desarrollo normativo hondureño desde la época post-independentista hasta el 2021, con el fin de verificar la armonización del estamento jurídico nacional con los avances del derecho internacional de los derechos humanos y el feminismo a nivel mundial. Este estudio identifica los principales vacíos legales en la normativa vigente, en aras de propiciar el debate sobre la explotación femenina, mejorar el marco jurídico actual y promover reformas encaminadas a garantizar una protección más adecuada para las mujeres.

PALABRAS CLAVE: Esclavitu d, género, trata de personas, legislación penal, bicentenario.

\section{ABSTRACT:}

Human exploitation has accompanied the evolution of humanity itself through time. Despite being an abolished and prohibited practice at all levels, it adapted to each era, even in Honduras. For this reason, from a legal point of view, this research work summarizes and analyzes the Honduran normative development from the post-independence period until 2021, to verify the harmonization of the national legal establishment with the advances of the international law of human rights and feminism worldwide. This study identifies some legal gaps in the current legal basis, to promote the debate on female exploitation, improve the legal framework and promote reforms to guarantee adequate protection for women.

KEYWORDS: Slavery, gender, human trafficking, criminal legislation, bicentennial.

Fecha de recepción: $28 / 4 / 2021$

Fecha de aprobación: 01/11/2021

1 Máster en Derechos Humanos y Derecho Humanitario, Universidad Panthéon - Assas Paris II (Grupo de Universidades de la Sorbona). Máster en Derecho Internacional Público, Universidad Panthéon - Assas Paris II (Grupo de Universidades de la Sorbona). Abogada egresada de la Universidad Nacional Autónoma de Honduras (UNAH). Asesora Jurídica en Abogados sin fronteras Canadá. Correo Electrónico: greyesvasquez@hotmail.com 


\section{INTRODUCCIÓN}

Laexplotación domésticaysexualdelas mujeres como actualmente la conocemos en Honduras, al igual que en el resto de las Américas, resulta ser una herencia de la época colonial. Aunque la esclavitud existía en los pueblos indígenas, era principalmente una medida de sanción penal, especialmente contra los prisioneros de guerra y no como medida para someter a las mujeres. Si bien, esa tradición española fue abolida formalmente con la independencia de las excolonias centroamericanas, su uso se modernizó y adaptó a las condiciones de vida de las sociedades hondureñas a través del tiempo.

Factores como la pobreza, la violencia, la discriminación interseccional que sufren las mujeres, su falta de acceso a la educación, oportunidades laborales y condiciones de vida indigna, las sitúan en situaciones de desventaja, empujándolas a trabajar en el ámbito privado para garantizar su subsistencia, y en su caso, la de sus dependientes. Tales aspectos exponen desproporcionalmente a las mujeres a entornos de explotación doméstica y sexual, los cuales han perdurado en estos 200 años de independencia y se han agudizado con pandemia global COVID-19, causando que hoy en día más personas del sexo femenino se vean expuestas a la explotación humana.

La violencia contra las mujeres se manifiesta de diversas formas, tanto en el ámbito público como en el privado, y a pesar del avance en el reconocimiento de los derechos de las mujeres a nivel mundial, muchos países todavía no cuentan con legislaciones adaptadas para proteger sus derechos y sancionar de forma efectiva las diversas formas de violencia como la esclavitud o explotación doméstica y sexual. En ese sentido, en el marco del bicentenario de la independencia centroamericana, el presente trabajo de investigación analiza los avances legislativos contra la esclavitud en Honduras en comparación con el desarrollo paralelo de estándares internacionales en la materia, especialmente bajo la perspectiva de género y el enfoque interseccional. El trabajo constituye un aporte a la armonización de la legislación del Estado hondureño con los instrumentos internacionales de derechos humanos.

El estudio de la normativa internacional y nacional ha permitido sintetizar la evolución del derecho penal en materia de esclavitud identificando, por un lado, avances como la adopción de leyes especiales y por otro, vacíos normativos como la falta de sanción al clientelismo de la esclavitud o servidumbre sexual y la inclusión de agravantes por la doble explotación femenina que ilustran su incompatibilidad con los estándares internacionales pero, sobre todo con las prácticas contemporáneas de esclavitud. A 200 años de abolición de la esclavitud en Honduras, el marco normativo continúa siendo deficiente para proteger a las mujeres de la esclavitud moderna.

\section{METODOLOGÍA}

La presente investigación se basa en un análisis histórico legal y doctrinal sobre la evolución del derecho penal hondureño contra la esclavitud femenina durante el bicentenario independentista. La explotación humana de forma general goza de invisibilidad en las sociedades, impide la recolección de estadísticas confiables u oficiales en la mayoría de Estados, incluso en Honduras. Por ello, la falta de información cuantitativa es la principal limitación de este trabajo. Sin embargo, esta investigación puede servir de base para que futuros estudios profundicen el análisis cuantitativo de la esclavitud femenina. 
Los avances del derecho internacional sobre derechos de las mujeres, la perspectiva de género y el enfoque interseccional son parte de la columna vertebral de este análisis. El enfoque cualitativo del estudio jurídico realizado a través de la revisión sistemática de la doctrina, de las primeras constituciones (1824-1880), de la totalidad de códigos penales hondureños (18802020), así como de otras leyes vinculadas al tema, instrumentos y jurisprudencia internacionales, permitió comparar doscientos años de evolución doctrinaria en materia penal en Honduras para prevenir y sancionar la esclavitud. El estudio se centra en la explotación sexual y doméstica de las mujeres, los avances simultáneos del derecho internacional de los derechos humanos y derechos de las mujeres en el tiempo. Con esta comparación se ha podido examinar si la tipificación de la esclavitud como delito se ajustó adecuadamente o no a las exigencias de protección de las mujeres de cada época contra estas formas de explotación humana.

\section{ANTECEDENTES HISTÓRICOS DE LA LEGISLACIÓN PENAL CONTRA LA ESCLAVITUD DE LAS MUJERES EN HONDURAS}

La esclavitud ha existido a lo largo de la historia de la humanidad, constituyendo un modo de dominación de un pueblo sobre otro. En algunas civilizaciones, esta práctica constituyó una forma de organización económica vinculada a la producción de bienes o estilo de vida de los pueblos. (Villalpando, 2014) Por otro lado, Saénz (2012) explica que, en el caso de los pueblos indígenas asentados sobre el actual territorio de Honduras, la esclavitud fue principalmente utilizada como una medida de sanción penal por la comisión de algunos delitos o para someter a los prisioneros de guerra.
En América, la esclavitud fue utilizada por los conquistadores para explotar las riquezas mineras y agrícolas del nuevo continente. Estas necesidades económicas generaron un gran comercio de esclavos y esclavas de África hacia América. (Villalpando, 2014) Sin embargo, cuando hablamos de la esclavitud de las mujeres durante la conquista, debemos mencionar las relaciones de poder y la violencia de género brutal ejercida sobre ellas. En aquella época, las leyes de la Corona Española se aplicaban en las colonias con base en diferencias raciales entre blancos, indígenas y negros. Esto permitió que los conquistadores españoles tomaran a muchas mujeres indígenas por la fuerza, sin que fueran sancionados por las leyes indianas y peninsulares. Así, la violación y el rapto de mujeres indígenas y negras pasaron a ser situaciones corrientes y normalizadas en la época. (Chirix García, 2019) La violencia y el machismo facilitaron la esclavitud de las mujeres, quienes además de servir como cargadoras y cocineras, fueron esclavas sexuales de los conquistadores. (Valladares, 2009)

Según Rodríguez M. (2014), la principal diferencia entre hombres esclavos y mujeres esclavas era su capacidad de reproducción, siendo éstas últimas una "cosa sexual" sujeta a la voluntad del dueño. Trabajaban igual que los varones y además debían reproducirse con el dueño o con otros esclavos para generar más riqueza para su amo: más mano de obra con sus hijos y su propia fuerza de trabajo en casa o en el campo. El doble sometimiento de las mujeres a la esclavitud doméstica y sexual fueron utilizadas como formas de intercambio de obediencia por protección según la doctrina y la historia (Mandel Katz, 2016), sentando las bases sociales de la época contemporánea. 
Es preciso resaltar que, en el tiempo de la conquista y la colonia, las mujeres no esclavas tampoco eran consideradas iguales en derechos que los hombres, excluyéndolas sistemáticamente de los privilegios de la ciudadanía. Para finales del siglo XVIII paralelo a la época de la colonia en América, tras la revolución francesa de 1789 se proclamaron los derechos del hombre y del ciudadano, no así de las mujeres. Olympe de Gouges - pionera feminista y militante de la abolición de esclavitud - autora de la Declaración de los Derechos de la Mujer y la Ciudadana fue guillotinada tras defender sus ideales políticos en 1793. (Kadish \& Massardier-Kenney, 1994)

Simultáneamente a finales del siglo XVIII surgieron en Inglaterra movimientos abolicionistas de las nuevas iglesias protestantes, seguidos en el siglo XIX por la Conferencia Internacional de Bruselas (1889 - 1890) que dispuso abolir la esclavitud y penalizar su comercio por las grandes potencias conquistadoras ${ }^{2}$. (Villalpando, 2014)

Con la independencia, las excolonias centroamericanas instauraban sus nuevos sistemas políticos separándose de la Corona Española y reivindicando derechos para sus ciudadanos, bajo el sueño que hoy profesa nuestro escudo: ser libres, soberanas e independientes.

\subsection{Abolición de la esclavitud en Honduras}

El 15 de septiembre de 1821 se firmó el Acta de Independencia de América Central proclamando la separación de las provincias centroamericanas ${ }^{3}$

2 Tales como Alemania, Austria, Bélgica, Dinamarca, España, Francia, Gran Bretaña, Holanda, Imperio Otomano, Italia, Persia, Rusia, Suecia y Noruega, adhiriéndose más tarde Japón, entre otras.

3 Guatemala, Honduras, El Salvador, Nicaragua y Costa Rica. de la Monarquía Española. Sin embargo, las jóvenes provincias mantuvieron las estructuras sociales impuestas por los españoles, incluyendo la práctica de la esclavitud. (Revista del Archivo y Biblioteca Nacionales, s.f.)

En 1824, la nueva República Federal de Centroamérica abolió la esclavitud en su primera Constitución en los términos siguientes: "Artículo 13. Todo hombre es libre en la República. No puede ser esclavo el que se acoja a sus leyes, ni ciudadano el que trafique en esclavos”. Una primera lectura del artículo 13 evidencia la herencia patriarcal en la nueva República al abolir la esclavitud declarando la libertad de "todo hombre" en lugar de toda persona. Cumes (2012) explica que lo colonial no se reduce a una dominación étnica, pues si analiza de forma interseccional, abarca otros campos como el género y la clase social con las que se configuran desigualdades. Montanaro Mena (2017) profundiza el concepto de colonialidad indicando que este proceso distingue categorías sociales opuestas en forma binaria y jerárquica - dentro de la especie humana: las mujeres como seres inferiores a los hombres - o atribuyendo la idea de superioridad de una raza sobre otra - los indígenas de las Américas y los africanos esclavizados clasificados como no humanos frente a los europeos.

Lamentablemente, la independencia no extinguió la colonialidad. Esta permaneció y continuó reproduciéndose, siendo el esquema que reorganizó y sigue reorganizando las formas de explotación del trabajo, asalariado o esclavo, de acuerdo a los parámetros de la raza. Desde ahí nacen las jerarquías sociales, las administraciones públicas y la subjetividad de los colonizados en las sociedades neo coloniales. (Montanaro Mena, 2017) En 1825, se redacta la primera Constitución del Estado de Honduras, quien, en su intento de 
garantizar los principios de libertad, igualdad, seguridad y propiedad, lo llevó a reproducir los patrones machistas estereotipados de las sociedades europeas del siglo XVIII. Su artículo 8 estipulaba que "Todos los hondureños son libres, y ciudadanos los que tengan la edad", excluyendo a toda mujer de los beneficios de la ciudadanía.

Previo a la independencia centroamericana, a mediados del siglo XVIII, nacía en Europa la primera ola del feminismo cuestionando los privilegios masculinos que fueron otorgados tras la revolución francesa, la revolución americana y la revolución industrial. Las mujeres exigían su reconocimiento como parte integral de la humanidad y rechazaban la jerarquía impuesta de lo masculino sobre lo femenino. Las exigencias se basaban en los principios universalistas de igualdad respecto al voto femenino, educación igualitaria, derechos como trabajadoras y de propiedad. (Gómez Yepes et al., 2019) En el nuevo continente, los derechos de las mujeres no eran debatibles, pues esta ola se desarrolló en América Latina hasta mediados del siglo XIX y principios del siglo XX. Durante los primeros años de Honduras como nación soberana, se mantuvo la diferencia entre lo público-masculino y lo privado-femenino, relegando las mujeres al trabajo reproductivo ${ }^{4}$ sin derechos civiles, políticos, económicos ni sociales, invisibilizando la esclavitud femenina.

Por ejemplo, Mariñas Otero (2008) indica que para el siglo XVIII, la esclavitud en Honduras

4 El trabajo reproductivo se extiende a aquellas actividades o tareas imprescindibles o necesarias para el mantenimiento de las personas, generalmente familiares, como son el cuidado de los cuerpos, la educación, la formación, el mantenimiento de las relaciones sociales y el apoyo psicológico a los miembros de la familia, así como el mantenimiento de los espacios $\mathrm{y}$ bienes domésticos. El trabajo de la reproducción incluye las actividades destinadas a atender el cuidado del hogar y de la familia. desaparecía progresivamente dada la falta de grandes plantaciones y minería en comparación con otras regiones. Sin embargo, los documentos de la época muestran que la esclavitud era principalmente doméstica ${ }^{5}$, ejercida en su mayoría por las mujeres indígenas o negras. Asimismo, Leticia (De Oyuela, 2001) describe como las mujeres del período post-independentista, incluso las de clase alta, quedaron al margen de la educación, de la ideología y de la corporeidad que organizaba la cultura de la época, permitiendo que ésta adquiriera una perspectiva masculina. Todas las mujeres siguieron viviendo dentro del lirismo del amor romántico, recluidas en un universo interno con sus emociones, reflexiones, sueños y fantasías, atrapadas en el círculo doméstico. Todavía a finales del siglo XIX, los jóvenes varones aprovechando la aceptación "natural" de sus padres realizaban sus primeros encuentros sexuales con las sirvientas de la casa. Para 1880, existía la costumbre de llevar al amo a jóvenes doncellas desamparadas y huérfanas, quienes serían primero del dueño de la casa y después del heredero (De Oyuela, 2001). Esto evidencia la naturalidad de la explotación sexual, el abuso de situaciones de necesidad, la violencia y la discriminación de las mujeres en esta época.

La segunda ola del feminismo marcada por la exigencia del reconocimiento de las mujeres como ciudadanas logró con el movimiento sufragista la consecución del voto femenino, acceso a la educación y al trabajo. (Gómez Yepes et al., 2019) Sin embargo, el voto femenino será reconocido en Honduras hasta $1955^{6}$ (De Oyuela, 2001), por lo que las mujeres hondureñas post-independentistas

5 Vid., por ejemplo, "Auto del Alcalde Mayor del Real de Minas de Tegucigalpa sobre el depósito de la mulata Paula el 11 de julio de 1678", reproducido en la Revista de la Sociedad de Geografía e Historia de Honduras, vol. XXXIV, pág. 24.

6 Decreto 30 de 1954 que ratificaba la Ley de Defensa del Régimen Democrático y los Derechos Políticos de la Mujer. 
permanecieron silenciadas por más de un siglo, siendo la explotación femenina imperceptible en el ámbito público.

Aunque la esclavitud se había reducido en Honduras, ésta se modernizó aprovechándose de las condiciones neo coloniales. Barahona (1995) explica como la sociedad hondureña del siglo XIX estuvo marcada por las desigualdades entre los ciudadanos "propietarios" que eran ricos ganaderos, terratenientes, agricultores y comerciantes que acapararon las tierras y riquezas y los excluidos "proletarios" descendientes de los indígenas y ladinos coloniales, mayoritariamente campesinos sin tierra, peones de las haciendas, sirvientes domésticos o artesanos de las ciudades quienes vivían en situaciones de extrema pobreza y miseria. Estos factores de vulnerabilidad y de necesidad de la clase proletaria facilitaron la proliferación de las nuevas formas de esclavitud en esta época, particularmente del servicio doméstico. En consecuencia, las mujeres, especialmente las pobres, enfrentaban situaciones de riesgo de explotación por no ser ciudadanas y por estar recluidas en el ámbito privado.

$\mathrm{Al}$ verificar las constituciones comprendidas entre 1839 a 1880 y los tres primeros códigos penales de Honduras entre 1880 a 1906 , se observa la falta de protección jurídica de las mujeres contra la servidumbre doméstica y la esclavitud sexual. Las primeras constituciones del Estado (1839 y 1848) están marcadas por el patrón machista de considerar como hondureños y ciudadanos únicamente a los hombres. Para 1839, la servidumbre doméstica suspendía el ejercicio de la ciudadanía de los hombres ${ }^{7}$ según mandato

7 Constitución del Estado de Honduras del 11 de enero de 1839. Artículo 6.- Son hondureños todos los nacidos y avecindados en el territorio del estado, y los extranjeros con carta de naturaleza. Artículo 9.- Son ciudadanos todos aquellos hondureños mayores de dieciocho años (...).

Artículo 12.- El ejercicio de la ciudadanía se suspende: (...) 3. constitucional, facilitando su explotación. Pero, las mujeres no eran protegidas de ninguna forma contra la esclavitud.

Con la instauración de la República a mediados del siglo XIX, se reconoce por primera vez a todas las personas nacidas en el territorio como hondureños proclamando la igualdad de derechos en las constituciones de 1865 y 1873. Cabe precisar que, aunque se reconociera constitucionalmente la igualdad entre hombres y mujeres, en la práctica no se reconocía el voto femenino ni el derecho a la educación superior ${ }^{8}$, entre otros. Y se vuelve a observar la suspensión de la ciudadanía por el ejercicio del servicio doméstico ${ }^{9}$, dejando en total desprotección a las sirvientas domésticas de esa época.

Por el de sirviente doméstico cerca de la persona; (...).

Constitución del Estado de Honduras del 5 de febrero de 1848. Artículo 6.- Son hondureños todos los nacidos en el territorio del Estado (...). Artículo 7.- Son ciudadanos todos los hondureños mayores de 21 años (...).Artículo 9.- Desde el año mil ochocientos sesenta en adelante, ningún hondureño será ciudadano, si no sabe leer, escribir y contar

8 La primera mujer egresada de la Universidad Nacional Autónoma de Honduras fue la Dra. Lucila Gamero en 1924. Le siguió la Dra. Corina Barahona en 1936. La primera abogada fue Alba Alonzo Cleaves quien egresó en 1946 y pudo ejercer la profesión sino hasta 1958. Presencia Universitaria (2017 y 2020). 9 Constitución de la República de Honduras del 29 de septiembre de 1865. Artículo 9.- Son hondureños: 1. Todas las personas nacidas en el territorio de la República; (...). Artículo 13.- Son ciudadanos todos los hondureños, mayores de veinte años que tengan oficio, o propiedad que les asegure un modo de vivir honesta y decentemente. (...).Artículo 16.- Se suspenden los derechos de ciudadano: (...) 5. Por ser sirviente doméstico cerca de la persona.

Constitución de la República de Honduras del 25 de diciembre de 1873. Artículo 8.- Son Hondureños: 1. Todas las personas nacidas en el territorio de la República; (...). Artículo 13.- Son ciudadanos todos los hondureños, mayores de veinte años que tengan oficio, o propiedad que les asegure un modo de vivir honesta y decentemente. También son ciudadanos, los mayores de dieciocho años que con las cualidades expresadas tengan grado literario, o sean casados. (...) Artículo 15.- Se suspenden los derechos de ciudadano: 5. Por ser sirviente doméstico cerca de la persona. 
Finalmente, Honduras declaró en la constitución de 1880 que "El esclavo que pise el territorio hondureño queda libre. El tráfico de esclavos es un crimen" y mantuvo el reconocimiento de la nacionalidad y la ciudadanía a todas las personas nacidas en el territorio ${ }^{10}$. Se observa de nuevo la reproducción de patrones machistas al indicar "el esclavo" en lugar de la persona esclava, invisibilizando la esclavitud doméstica y sexual sufrida por las mujeres como resultado de su exclusión sobre la vida pública de la sociedad hondureña.

El 27 de agosto de 1880 se adoptó el primer código penal sin prever delitos contra la esclavitud, a pesar de ser una práctica abolida en territorio hondureño. Sin embargo, existen tres elementos importantes en este código. En primer lugar, el artículo 369 sancionaba la promoción o facilitación de la prostitución o corrupción de menores a través del abuso de autoridad o confianza. Si bien, no es una protección específica para las mujeres contra la esclavitud sexual, lo era para los niños y las niñas. En segundo lugar, el artículo 370 preveía la sanción del rapto, la violación y el estupro, que son delitos de agresión sexual generalmente cometidos contra las mujeres, incluyendo en contextos de explotación humana. Por último, el artículo 13 incluía entre las circunstancias agravantes de la responsabilidad criminal: 1) el abuso de la superioridad del sexo del delincuente $\left(n^{\circ} 6\right)$ y 2$)$ que el hecho fuera ejecutado con ofensa o desprecio de la edad o sexo del ofendido $\left(\mathrm{n}^{\circ} 20\right)$. Aunque no se preveía una disposición que protegiera a las mujeres contra la esclavitud, existían circunstancias

10 Constitución de la República de Honduras del 1 de noviembre de 1880. Artículo 8.- El esclavo que pise el territorio hondureño queda libre. El tráfico de esclavos es un crimen. Artículo 29.- Son hondureños las personas que nacen en el territorio de la República, y las que se naturalizan en el país conforme a la ley. Artículo 32.- Son ciudadanos: 1. Todos los hondureños naturales o naturalizados mayores de veintiún años, que tengan profesión, oficio, renta o propiedad que les aseguren la subsistencia; (...). agravantes vanguardistas con enfoque de género encaminadas a proteger a las mujeres y las niñas respecto a situaciones desiguales de poder frente a los agresores.

En el código penal de 1895 que entró en vigencia hasta 1899, sí contemplaba una disposición específica contra la esclavitud en el artículo 128: "El tráfico de esclavos será penado con presidio mayor en su grado máximo". Dicha disposición no sanciona per se la práctica esclavista sino más bien el tráfico o comercio de esclavos, creando una protección limitada considerando que en dicha época la esclavitud clásica había desaparecido y las prácticas esclavistas se había modernizado. Tampoco había una protección especial de las mujeres contra la esclavitud sexual ni doméstica. El artículo 436 hacía la diferencia entre mujeres de buena fama y mujeres que no son de buena fama para sancionar el rapto, incurriendo en una clara discriminación de las mujeres por razón de su clase social. La prostitución o corrupción de menores (art.435) y la violación (art.429) se sancionaba casi con los mismos criterios del código anterior.

En 1906, el código penal militar dirigido a regir las sanciones penales bajo el fuero militar, provocó que delitos como la violación, el estupro o el rapto (art. 220 y 333 ) cometidos por militares contra civiles fueran conocidos por los tribunales militares especiales, propiciando la violación de derechos de las mujeres agredidas. De igual forma, el artículo 215 evidencia que la práctica de la servidumbre ${ }^{11}$ era todavía tolerada ${ }^{12}$.

11 Artículo 215- El militar que, hallándose en acto del servicio o con ocasión de él, mate a una persona o ejecute el mismo delito, en cuartel, campamento, vivac, fortaleza, obra militar, almacén, oficina, fundición, maestranza, fábrica, parque, academia y demás establecimientos o dependencias de guerra, en casa de oficial o en la que el culpable estuviere alojado, si la víctima fuese el dueño o alguno de su familia o servidumbre, se castigará con la pena de presidio mayor en su grado máximo a muerte. (...)

12 Del artículo 215, se observa como este delito hace extensiva la protección del "amo", su familia y su servidumbre 
Este primer análisis de la legislación hondureña en materia de esclavitud, demuestra que la protección contra esta práctica se adaptaba parcialmente a los avances del movimiento abolicionista. No así, a la protección específica de las mujeres contra la esclavitud sexual y doméstica. Por lo que, se analizará la evolución del derecho penal hondureño en relación a la evolución de los estándares internacionales contra la esclavitud.

\subsection{Primeros estándares internacionales contra la esclavitud y el código penal de 1984}

A inicios del siglo XX, tras la primera guerra mundial, la Sociedad de Naciones encargó a una comisión temporal la tarea de preparar un instrumento que aboliera y sancionara la esclavitud. (Villalpando, 2014) La Convención sobre la Esclavitud de 1926 (en adelante C1926) fue el primer instrumento de carácter universal que estableció estándares internacionales en esta materia. Definió el concepto clásico de esclavitud como "el estado o condición de un individuo sobre el cual se ejercitan los atributos del derecho de propiedad o algunos de ellos" y por primera vez a nivel internacional se adopta el concepto de trata de esclavos ${ }^{13}$. También fijó obligaciones internacionales para prevenir, reprimir la trata de esclavos y sobre todo suprimir completa y progresivamente la esclavitud en todas sus formas (artículo 2). Y hace hincapié en evitar que el trabajo forzoso $\mathrm{u}$ obligatorio genere condiciones análogas a la esclavitud para lo cual los Estados deben adoptar las medidas pertinentes (artículo 5).

o trabajadores en condiciones indignas, como si fuese algo normal o natural en la sociedad.

13 Comprende todo acto de captura, adquisición o cesión de un individuo para venderle o cambiarle; todo acto de cesión por venta o cambio de un esclavo, adquirido para venderle o cambiarle, y en general todo acto de comercio o de transporte de esclavos.
Villalibre (2009) explica que la esclavitud en sentido clásico integra cuatro elementos: 1) La noción de propiedad, siendo el ejercicio de control absoluto sobre las víctimas utilizando la amenaza, la violencia $u$ otro tipo de coacciones físicas y/o morales, para mantenerlo; así como sus objetos personales y relaciones prohibidas con el exterior. 2) El sometimiento, identificado con la reacción de las víctimas ante la toma de decisión sobre ellas. Este solo es un indicador que no reconoce el consentimiento de la víctima como un factor determinante. 3) La deshumanización, que refleja el grado de explotación al que se somete a una persona vulnerando la dignidad humana y desconociendo su estatus legal como persona. 4) La alineación de la libertad personal y de movimiento. Niega todo patrimonio, excluye familiar y culturalmente, carece de vida privada y le obliga a residir en casa del "dueño" o en su lugar de trabajo.

Sobre estos cimientos, la Organización Internacional del Trabajo (en adelante OIT) adoptó en 1930 el Convenio sobre el trabajo forzoso (en adelante C29) definiendo la expresión trabajo forzoso u obligatorio como "todo trabajo o servicio exigido a un individuo bajo la amenaza de una pena cualquiera y para el cual dicho individuo no se ofrece voluntariamente", obligándose los Estados suscriptores a suprimir esta forma de explotación laboral.

Tras la segunda guerra mundial, la Declaración Universal de Derechos Humanos (1948) ${ }^{14}$ y su reconocimiento mundial reafirmó la prohibición de la esclavitud y la trata de esclavos ampliando la protección de las personas contra la servidumbre. Por esa razón, en 1956 se adopta la Convención suplementaria sobre la abolición de la esclavitud, 14 Honduras fue uno de los países signatarios de la Carta de las Naciones Unidas desde su fundación en 1945, por lo que formaba parte de la Asamblea General que adoptó la DUDH. 
la trata de esclavos y las instituciones y prácticas análogas a la esclavitud (en adelante C1956) para ampliar el alcance y la precisión de la C1926. Este instrumento mantuvo los conceptos de esclavitud y trata de esclavos, profundizó otras circunstancias análogas a la esclavitud como la servidumbre por deudas ${ }^{15}$ y la servidumbre de la gleba ${ }^{16}$, y por primera vez abordó situaciones particulares como la dependencia de las mujeres ${ }^{17}$ y la protección de los niños ${ }^{18}$. También incluye obligaciones de adoptar medidas legislativas o de cualquier índole para abolir o abandonar progresivamente las situaciones análogas a la esclavitud. En 1957, la OIT adoptó el Convenio sobre la abolición del trabajo forzoso (en adelante C105) reforzando así las obligaciones de los Estados para tomar medidas eficaces para abolir esta forma de explotación laboral en el mundo, incluyendo en la servidumbre doméstica.

15 El estado o la condición que resulta del hecho de que un deudor se haya comprometido a prestar sus servicios personales, o los de alguien sobre quien ejerce autoridad, como garantía de una deuda, si los servicios prestados, equitativamente valorados, no se aplican al pago de la deuda, o si no se limita su duración ni se define la naturaleza de dichos servicios.

16 La condición de la persona que está obligada por la ley, por la costumbre o por un acuerdo a vivir y a trabajar sobre una tierra que pertenece a otra persona y a prestar a ésta, mediante remuneración o gratuitamente, determinados servicios, sin libertad para cambiar su condición

17 Toda institución o práctica en virtud de la cual: i) Una mujer, sin que la asista el derecho a oponerse, es prometida o dada en matrimonio a cambio de una contrapartida en dinero o en especie entregada a sus padres, a su tutor, a su familia o a cualquier otra persona o grupo de personas; ii) El marido de una mujer, la familia o el clan del marido tienen el derecho de cederla a un tercero a título oneroso o de otra manera; iii) La mujer, a la muerte de su marido, puede ser transmitida por herencia a otra persona.

18 Toda institución o práctica en virtud de la cual un niño o un joven menor de dieciocho años es entregado por sus padres, o uno de ellos, o por su tutor, a otra persona, mediante remuneración o sin ella, con el propósito de que se explote la persona o el trabajo del niño o del joven.
Simultáneamente, los años cincuenta en Honduras estuvieron marcados por diversos cambios sociales. Tras la histórica huelga de 1954 promovida por los trabajadores y las trabajadoras "bananeros" se creó el primer código del trabajo en 1959 aún vigente en 2021. Torres Calderón destaca el aporte significativo de las mujeres en esa lucha, siendo las pioneras en utilizar la huelga como instrumento para reclamar sus derechos, evidenciar situaciones de explotación laboral y exigir una justicia social. Así lograron asumir el control de las fábricas y provocar la negociación entre los comités de huelga organizados por ellas y sus patronos. Durante la huelga del 54, en las plantaciones bananeras propusieron la creación de un sindicato integrado por ellas. Este no logró ser creado y obligó a muchas mujeres a retornar a los invisibles puestos de trabajo en sus hogares sin haberse alcanzado la obtención de una organización femenina con características propias a sus intereses y necesidades. (De Oyuela, 2001) Teresina Rossi Matamoros, expresidenta del Comité Técnico Ejecutivo de la Huelga en Tela, recuerda en su testimonio como desde su posición y aprovechando la coyuntura del momento, intentaba cambiar la mentalidad de la sociedad a través de sus discursos. Cuestionaba el rol de las mujeres como amas de casa y de la necesidad de darles el puesto que le correspondía como trabajadoras luchadoras de clase al lado de los hombres, razón por la que no debían mantenerlas todo el tiempo en esa condición de sometimiento. (Barahona, 2004) Por otro lado, con la llegada de la primera y la segunda ola del feminismo a Honduras, las mujeres se organizaron hasta alcanzar el voto femenino y la ciudadanía al año siguiente en 1955. A pesar de estos avances en el reconocimiento de los derechos de las mujeres, el recién adoptado código del trabajo excluía de su 
protección el servicio doméstico, permitiendo así la continuidad de la explotación de las mujeres que trabajan en este sector informal ${ }^{19}$.

Retomando las obligaciones internacionales, el Pacto internacional de derechos civiles y políticos (en adelante PIDCP) de $1966^{20}$ también integra la prohibición de la esclavitud, servidumbre y trabajo forzoso, precisando las circunstancias que no constituyen trabajo forzoso u obligatorio ${ }^{21}$. A nivel regional, se adoptó la Convención Americana sobre Derechos Humanos (en adelante $\mathrm{CADH}$ ) de $1969^{22}$ que prohíbe la esclavitud, servidumbre $\mathrm{y}$ trabajo forzoso $\mathrm{u}$ obligatorio, especialmente todas las formas de trata de mujeres.

19 El artículo 151 del código del trabajo describe las labores a desarrollar en el trabajo doméstico entre los que se encuentran las amas de llaves, nodrizas, cocineras, ayas, choferes particulares, sirvientes, niñeras, lavanderas y los de otros oficios de esta misma índole. El Artículo 153 expone sobre el derecho a recibir un salario, alimentación de calidad corriente y habitación, pero no especifica el salario que devengará.

20 Suscrito por Honduras mediante Acuerdo No.10 del 22 de abril de 1980. Ratificado por Decreto No. 961 de la Junta Militar de Gobierno en Consejo de Ministros del 18 de junio de 1980. Publicado en el Diario Oficial "La Gaceta" No.

23,167 del 30 de julio de 1980.

21 Artículo 8 numeral c) No se considerarán como "trabajo forzoso u obligatorio", a los efectos de este párrafo: i) Los trabajos o servicios que, aparte de los mencionados en el inciso b), se exijan normalmente de una persona presa en virtud de una decisión judicial legalmente dictada, o de una persona que habiendo sido presa en virtud de tal decisión se encuentre en libertad condicional; ii) El servicio de carácter militar $\mathrm{y}$, en los países donde se admite la exención por razones de conciencia, el servicio nacional que deben prestar conforme a la ley quienes se opongan al servicio militar por razones de conciencia. iii) El servicio impuesto en casos de peligro o calamidad que amenace la vida o el bienestar de la comunidad; iv) El trabajo o servicio que forme parte de las obligaciones cívicas normales.

22 Aprobada por Honduras mediante el Acuerdo No. 8, el 22 de noviembre de 1976. Ratificada mediante Decreto No. 523 del Jefe de Estado en Consejo de Ministros, el 26 de agosto de 1977. Publicada en el Diario Oficial "La Gaceta" No. 22,287289, e1 $1^{\circ}$ de septiembre de 1977.
Durante los años sesenta, la tercera ola del feminismo comienza a cuestionar el sistema patriarcal androcentrista con mayores exigencias por la igualdad de género, promoviendo la autoevaluación del feminismo para volver al movimiento de liberación de las mujeres más inclusivo. (Gómez Yepes et al., 2019). Esta era trajo herramientas como el enfoque de género ${ }^{23}$ y la interseccionalidad ${ }^{24}$ en la discriminación, fundamentales para el presente estudio, que facilitan el análisis de las vulnerabilidades frente a la explotación humana en relación a las particularidades específicas de cada víctima y permiten visibilizar el fenómeno de doble esclavitud femenina. En el Decenio de las Naciones Unidas para la Mujer se adoptó a nivel universal la Convención sobre la eliminación de todas las formas de discriminación contra las mujeres (en adelante CEDAW) de 197925, creando obligaciones internacionales de adoptar medidas de carácter legislativo u otras apropiadas

23 El enfoque de género es una herramienta que nos permite identificar y caracterizar las particularidades contextuales y situaciones vivenciadas por las personas de acuerdo con su sexo y a los constructos sociales asociados con dicho sexo, con sus implicaciones y diferencias económicas, políticas, psicológicas, culturales y jurídicas, identificando brechas y patrones de discriminación. Disponible en: https://www.dane. gov.co/index.php/estadisticas-por-tema/enfoque-diferencial-einterseccional/enfoque-de-genero

24 En el año 1989, Kimberlé Crenshaw definió la discriminación interseccional como aquella en la que varios motivos de discriminación interactúan simultáneamente, de manera inseparable, provocando situaciones de exclusión social y vulnerabilidad. A modo de ejemplo: una mujer negra con discapacidad posee tres motivos de discriminación que la sitúan en mayor desventaja frente a una mujer negra o a un hombre negro. Disponible en: https://www.eldiario.es/ catalunya/dones-en-xarxa/igualdad-discriminacion-de-generodiscriminacion-interseccional $132 \quad 3190785 . \mathrm{html}$

25 Aprobada por Honduras mediante Acuerdo No. 12 de la junta Militar de Gobierno del 14 de mayo de 1980. Ratificada por Decreto No. 979 de la Junta Militar de Gobierno del 14 de julio de 1980. Publicado en el Diario Oficial "La Gaceta" No. 23,203 del 10 de septiembre de1980. Deposito: 3 de marzo de 1983. 
para suprimir todas las formas de trata de mujeres y la explotación de la prostitución de la mujer. Y a nivel regional, la Convención Interamericana para prevenir, sancionar y erradicar la violencia contra la mujer "Convención Belem Do Pará” (1994) ${ }^{26}$ reconoce la prostitución y la trata de personas como una forma de violencia contra la mujer.

Al analizar el código penal de 1984 junto a sus reformas ${ }^{27}$ a la luz de todos los estándares internacionales señalados, se observa la ausencia de sanción de la trata de mujeres, la esclavitud, la servidumbre y el trabajo forzoso, limitándose a castigar la explotación sexual y explotación económica. El artículo 154-A define la explotación sexual comercial como "la utilización de personas en actividades con fines sexuales donde existe un pago o promesa de pago para la víctima o para un tercero que comercia con ella”, ofreciendo un catálogo de delitos para sancionar este tipo de explotación humana.

Sin embargo, la mayor parte de delitos de explotación se enfocaban en proteger a la niñez y la adolescencia. Así los delitos de exposición de personas en centros de explotación sexual, el uso de personas en exhibiciones o espectáculos públicos o privados de naturaleza sexual, el acceso carnal o actos de lujuria a cambio de pagos o retribuciones en especie, la pornografía y la explotación económica, incluyendo por trabajo doméstico, se sancionaban únicamente cuando eran cometidos contra personas menores de dieciocho (18) años, dejando totalmente desprotegidas a las mujeres mayores de edad.

26 Ratificada por Honduras mediante Decreto No. 72-95 por el Congreso Nacional, el 25 de abril de 1995. Publicada en el Diario Oficial “La Gaceta” No. 27,678, el 14 de junio de 1995. 27 Código Penal de Honduras (1984), Decreto 144-83 con sus reformas hasta 2014. Disponible en: http://www.poderjudicial.gob.hn/CEDIJ/Leyes/Documents/C\%C3\%B3digo\%20 Penal\%20(Actualizado\%20a\%C3\%B10\%202014).pdf
Los únicos delitos de protección general eran el proxenetismo y el turismo sexual sancionados cuando se cometían contra cualquier persona, independientemente de su edad o su género. Respecto a las agravantes, el abuso de poder por razón de confianza, parentesco o jerarquía sobre la víctima permitía sancionar las relaciones desiguales de poder en contextos de explotación de mujeres, si se aplicaba un enfoque de género. $\mathrm{Y}$ aunque no se preveían delitos que protegieran específicamente a las mujeres contra la esclavitud doméstica, se puede rescatar la agravante del delito de proxenetismo que aumentaba en un medio $(1 / 2)$ la pena cuando se sometía a la víctima a condiciones de servidumbre u otras prácticas análogas a la esclavitud ${ }^{28}$, siendo la primera disposición que sanciona la doble explotación de las mujeres.

El análisis refleja que el recién derogado código penal no cumplía con los estándares internacionales de protección de las mujeres contra la trata de personas. Al sancionar únicamente la explotación sexual comercial se toleraba cualquier otra forma de explotación sexual que produjera otro tipo de beneficios materiales o personales. Asimismo, la ausencia de sanción contra la esclavitud, servidumbre, trabajo o servicio forzado dejaba en total desprotección a las mujeres contra la esclavitud o servidumbre doméstica.

Considerando la evolución de las sociedades y del derecho, el siglo XXI trajo consigo nuevos avances para luchar contra la explotación humana y Honduras adoptó nuevas leyes en la materia. Por lo que, se analizó la armonía entre estándares internacionales y la nueva legislación vigente aún en 2021.

28 Ibid. Artículo 148 numeral 4.

Revista de Derecho. Vol. 42, No. 1, Año 2021 $\mid-83$ 
IV. SITUACIÓN CONTEMPORÁNEA DE LA LEGISLACIÓN PENAL CONTRA LA ESCLAVITUD DE LAS MUJERES EN HONDURAS

4.1. Prohibición de la esclavitud como una modalidad de la trata de personas y las obligaciones internacionales del Estado de Honduras en el siglo XXI

El siglo XXI comenzó marcando un hito en la protección contra la explotación humana a nivel mundial. El Protocolo para prevenir, reprimir y sancionar la trata de personas, especialmente Mujeres y Niños (en adelante Protocolo de Palermo) que complementa la Convención de las Naciones Unidas contra la Delincuencia Organizada Transnacional en el 2000, alcanzó un acuerdo internacional para definir el delito de trata de personas, considerando que éste no conoce fronteras y por la necesidad de consolidar la cooperación internacional para combatirlo. Según el artículo 3 , se comete la trata de personas al ejecutar uno de los verbos rectores (captación, transporte, traslado, acogida y recepción de personas), recurriendo a uno de los medios (amenaza, uso de la fuerza, otras formas de coacción, rapto, fraude, engaño, abuso de poder, abuso de una situación de vulnerabilidad, concesión o recepción de pagos o beneficios para obtener el consentimiento de una persona que tenga una autoridad sobre otra), con un fin de explotación de la persona, estableciendo modalidades "mínimas" que los Estados deben contemplar a nivel interno (prostitución ajena, explotación sexual, trabajos o servicios forzados, esclavitud o prácticas análogas, servidumbre o extracción de órganos). La Oficina de las Naciones Unidas contra la Droga y el Delito (en adelante UNODC) (2010.b) ha aclarado que no es necesario que se haya configurado la

84-|Revista de Derecho. Vol. 42, No. 1, Año 2021 explotación para que exista el delito. Bastará la intención manifiesta de explotar a la persona, al recurrir a verbos rectores y medios. Así, el Protocolo de Palermo impone una obligación de tipificar el delito en las legislaciones internas de los Estados Parte conforme a sus parámetros.

Como ya se demostró, las formas de esclavitud no desaparecieron, solo se transformaron y adaptaron a las condiciones de vida actual, aprovechándose de la globalización, las nuevas tecnologías de la información y comunicaciones (TIC), la sobrepoblación mundial, la pobreza endémica, la aparición del crimen organizado, la corrupción a nivel global $^{29}$, entre otras. (Villalpando, 2014) Por esa razón, la Corte Interamericana de Derechos Humanos (en adelante Corte IDH), evolucionó el concepto de esclavitud a nivel regional en el caso trabajadores de la hacienda Brasil verde vs Brasil (2016). Con la interpretación evolutiva explicó que este concepto "ya no se limita a la propiedad sobre las personas" y planteó dos elementos que permiten ilustrar la esclavitud moderna o contemporánea: a) el estado o condición de un individuo, es decir la situación de jure o de facto de la esclavitud que no requiere la existencia de un documento formal o una norma legal que refleje el fenómeno en un sentido clásico; y b) el ejercicio de alguno de los atributos del derecho de propiedad. El esclavizador ejerce poder o control sobre la persona esclavizada anulando la personalidad de la víctima. El elemento de "propiedad" deber ser comprendido como la "posesión" o la demostración del control

29 Estos delitos proliferan sobre la base del soborno, la "vista gorda" de funcionarios y políticos, la obstrucción a las investigaciones, la complicidad en actos menores pero esenciales al crimen mayor y las múltiples variaciones de la inmoralidad. La persistencia de la esclavitud en buena medida refleja la crisis ética individual que a veces parece superar los ideales de justicia e igualdad del género humano. 
de una persona sobre otra, equiparándose a la pérdida de la propia voluntad o una disminución considerable de la autonomía personal.

A diferencia de la definición de Villalibre, la Corte IDH hace mayor énfasis en el ejercicio de los atributos del derecho de propiedad, sin exigir que necesariamente haya privación de la libertad personal y de movimiento. El análisis de este órgano judicial se centra principalmente en la demostración del control a través de aspectos psíquicos como la propia voluntad o la autonomía personal, en lugar de la propia libertad, considerando que hoy en día, la explotación humana tiene dos objetivos principales: a) la explotación laboral, incluyendo la mano de obra infantil; y b) la explotación sexual que tiende a ser acompañada por algún tipo de violencia y es la más frecuente a nivel mundial. (Villalpando, 2014)

La explotación laboral contemporánea suele ocurrir en el trabajo doméstico de una casa con tareas de cocinar, lavar, limpiar, encargarse del jardín, ejercer de chófer y cuidar a los niños, a los ancianos y a las mascotas. (Gulnara Shahinian, 2010) Al mantenerse en el ámbito privado, los y las trabajadores(as) viven con sus empleadores(as), lo cual erróneamente justifica que se escape del control social o del propio Estado. La víctima puede ser considerada como "miembro de la familia" facilitando la inexistencia de un acuerdo contractual con derechos y obligaciones mutuos y aumentando el riesgo de invasión intolerable a su espacio y libertades personales, sometiéndole así a situaciones de servidumbre o esclavitud doméstica. Bandé et al. (2019) afirman que esta explotación está tan feminizada como la pobreza, siendo las víctimas en su mayoría mujeres, en especial, jóvenes y pobres. Las creencias culturales y sociales permiten y aceptan violentar derechos laborales o someter a una mujer a servidumbre

ISSN: 2521-5159 (En Línea) o esclavitud doméstica cuando se le ofrece alojamiento y alimentación a cambio de trabajo en virtud de la asignación de roles de género sobre lo femenino. (Henao, 2012) Por esa razón, la jurisprudencia internacional ha reafirmado la obligación de contemplar una legislación penal adecuada para prevenir y sancionar la esclavitud, la servidumbre y el trabajo forzado u obligatorio ${ }^{30}$, contenida en los tratados mencionados ${ }^{31}$.

Por su parte, Rodríguez M. (2014) afirma que la explotación sexual también se asienta en la estructura de dominación del género masculino sobre el femenino, permitiendo generalmente que los hombres obtengan ganancias o beneficios al utilizar sexualmente a las mujeres que se enfrentan a factores de riesgo como la violencia, la pobreza, la discriminación y las desigualdades económicas, sociales, educativas y de formación (Guisasola Lerma, 2019). La naturalización de la "cosificación" 32 de las mujeres facilita su explotación sexual sin que se usen de barrotes, violencia brutal o castigos corporales $y$ psicológicos continuos, aunque sean frecuentes en una buena parte de los casos. Tampoco es un fenómeno visible en la esfera pública porque los lugares de explotación como los prostíbulos, cabarets, bares, entre otros, son visitados por hombres.

Según Henao (2012), existe una íntima relación entre la violencia basada en género y la explotación de las mujeres en el servicio doméstico y la industria del sexo. Al analizar la trata de personas con enfoque de género se puede visibilizar el rostro masculino de la explotación.

30 Tribunal Europeo de Derechos Humanos. Caso Siliadin v. Francia. Demanda $N^{\circ} 73376 / 01$. Sentencia del 26 de julio 2005. Párrs. 147, 148 y razón 2 p.36.

31 PIDCP, artículo 2; CADH, artículo 2; CEDAW, artículo 6; Convención Belem do Pará, artículo 7.e; Protocolo de Palermo, artículo 5.2.a).

32 Considerar y tratar como cosa a alguien o algo que no lo es.

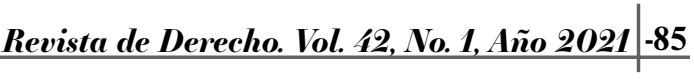


Así, en el caso de la explotación sexual se identifica al tratante, proxeneta o propietario del prostíbulo que se lucra de la explotación y al anónimo «consumidor» de prostitución sin el cual no habría negocio. De allí se desprende la necesidad de penalizar al cliente de la explotación sexual para frenar la demanda, al ser cómplice no solo de la explotación sino de la consolidación e invisibilización de la violencia estructural contra las mujeres. (Thill y Giménez Armentia, 2016; Guisasola Lerma, 2019) Esta obligación de sancionar la participación de los clientes se prevé en el artículo 5.2.b) del Protocolo de Palermo.

Los avances a nivel internacional concuerdan con la cuarta ola del feminismo desarrollada a partir de la segunda década del siglo XXI. En esta era se refuerza la exigencia de igualdad de derechos con enfoque interseccional, analizando las diferencias étnicas, raciales y culturales, así como las jerarquías entre las mujeres (Gómez Yepes et al., 2019), que se aplica en el contexto de la explotación femenina. Ha crecido y poco a poco se consolida la sororidad entre mujeres, fomentando la empatía y la cooperación entre ellas como pacto político para defenderse de las injusticias del patriarcado. (Bruna, 2021) La legislación vigente en Honduras se analizó a la luz de la evolución de obligaciones internacionales para contrastar la protección de las mujeres contra la explotación sexual y doméstica.

\subsection{La esclavitud moderna del siglo XXI y el ordenamiento jurídico hondureño para sancionar la explotación humana, en especial de las mujeres}

Debido a la cifra negra o sub-registro de $\operatorname{casos}^{33}$ de esclavitud moderna del siglo XXI en

33 No hay un registro exacto de cuántas trabajadoras domésticas hay en Honduras, el INE en los últimos datos que

86-|Revista de Derecho. Vol. 42, No. 1, Año 2021
Honduras, se recurrió a la revisión sistemática de la literatura para identificar las características de explotación doméstica y sexual de las mujeres con perspectiva de género y enfoque interseccional. Con ello, el análisis jurídico de la legislación penal vigente en Honduras se realizó en base a dichos arquetipos para verificar si la misma es adecuada para prevenir y sancionar ambas formas de explotación femenina.

La identificación de factores de riesgo frente a la explotación humana permite ajustar las normas jurídicas para sancionar de forma efectiva los fenómenos delictivos como la esclavitud moderna. Cuando hablamos de explotación humana debemos reconocer, por ejemplo, que el sistema económico capitalista y la estructura político-social patriarcal que operan en Honduras se refuerzan mutuamente al ser ambos sistemas de opresión de clases y de género, logrando naturalizar la discriminación, la violencia y la explotación de las mujeres. Eso explica que el perfil de las víctimas de trata de personas en Honduras corresponda principalmente a mujeres jóvenes y adolescentes con escasas oportunidades educativas y afectadas por la inequidad laboral. (O’Neill, 2019) El trabajo doméstico es ejercido en su mayoría por niñas, adolescentes y jóvenes campesinas en especial de origen indígena ${ }^{34}$ que comienzan a trabajar desde muy temprana edad para generar ingresos para sus familias, migrando del campo a la ciudad. Los modelos sociales y culturas vigentes han permitido la inserción laboral de otras mujeres de ingresos medios y altos $^{35}$ gracias a las trabajadoras domésticas,

sacó en el 2018, dice que hay alrededor de 134 mil, pero para mí que hay un sub-registro". Miriam Suazo, coordinadora de proyectos del CEM-H, mayo 2019.

34 Algunas palabras peyorativas para descalificar el trabajo doméstico de las mujeres son: nacha, sirvienta, natacha, muchacha, cipota, trabajadora, india.

35 Su trabajo ha sido fundamental para facilitar la inserción laboral de muchas mujeres de sectores de ingresos medios y

ISSN: 2509-5296 (Impreso) 
naturalizando y ocultando la explotación. Cuando poseen una baja escolaridad y desconocen la ciudad y sus derechos, se aumenta el riesgo de cautiverio, discriminación y violencia al que son sometidas sin que denuncien los abusos. La mayoría al no lograr insertarse en el sistema educativo ni adquirir otra formación profesional no pueden mejorar sus condiciones económicas perpetuando así su situación de esclavitud. Los abusos incluyen la ausencia de protección social y de un contrato de trabajo, largas jornadas de trabajo con salarios injustos y sin reconocimiento de horas extra, sanciones monetarias por “desobediencia”, violencia psicológica ${ }^{36}$ o abuso sexual, entre otros. (Bandé et al., 2019)

Respecto a la explotación sexual, las mujeres, niñas y jóvenes siguen siendo las poblaciones más vulnerables al ser las más afectadas por la desigualdad, la pobreza, la marginalidad, la violencia, la falta de oportunidades y las necesidades básicas no satisfechas ${ }^{37}$ que se han incrementado debido al COVID-19. (CICESCT, 2020) La proliferación de las TIC y el auge de las redes sociales ha facilitado la captación de las mujeres y las niñas ${ }^{38}$ (O’Neill, 2019) a través

altos, que contratan apoyo doméstico ante la insuficiencia de políticas de conciliación entre el trabajo y la familia en sus países. Esto permite a las familias que contratan trabajo doméstico disponer de más tiempo y a los niños y otras personas dependientes recibir los cuidados que requiere.

36 Gritos, humillaciones que sufren van desde no tener un lugar digno donde comer, darles comida diferente a la de los empleadores o darles las sobras, separar sus cubiertos, vasos y platos como si se tratará de una persona con una enfermedad infecto contagiosa, dormir en las áreas de lavado sin privacidad, mantenerlas cautivas, encerradas, sobre todo las que llegan del interior y que son menores de edad, no respetarles su descanso los domingos cuando ellas, por no contar con parientes o amigas a quien visitar.

37 Como acceso a medios de subsistencia y de vida, servicios básicos de salud, educación, vivienda, alimentación, falta de dinero para pagar el alquiler.

38 La situación derivada de la pandemia, ha permitido que ciberdelincuentes capten a las víctimas para ser explotadas a de amenazas, engaños como falsas amistades y noviazgos, ofertas de empleo fraudulentas, ofrecimientos de mejores condiciones de vida o ayuda económica. (CICESCT, 2020) Este tipo de explotación opera disfrazada en negocios aparentemente lícitos como bares, cantinas, night club, discotecas, hoteles, casas de masajes, casas particulares para clientes específicos (CICESCT, 2018; CICESCT, 2020), dificultando identificación de las víctimas. Túnez (2014) explica que socialmente se intenta separar la prostitución "libre" de la forzada por la naturalización de la cosificación de la mujer en la industria del sexo y acertadamente se cuestiona sobre la existencia de una esclavitud voluntaria, en especial cuando se trata de explotación sexual. En realidad, la cultura promueve y tolera la explotación sexual de mujeres, protegiendo a los clientes tras invisibilizarlos social y jurídicamente, aunque son cómplices de este delito que comercia con la sexualidad de las mujeres. (O’Neill, 2019)

Por las características de la explotación doméstica y sexual en Honduras, es necesario incluir un enfoque de género interseccional en todas las leyes y políticas destinadas a combatir la trata de personas, conforme a la CADH, CEDAW y Convención Belem do Pará. Al reconocer las desigualdades y reflexionar sobre las relaciones de poder sexualizadas junto con la discriminación por raza, clase social y origen (Palumbo, 2018), se puede sancionar de manera efectiva la comisión de este delito. La protección contra la explotación sexual incluye la sanción de las personas explotadoras, a los clientes por perpetuar la oferta y demanda de mujeres, y a las personas naturales o jurídicas dueñas de locales de explotación. Para la servidumbre o esclavitud doméstica, se debe prever la sanción de los patronos que incurren en graves violaciones a los derechos laborales través de la WEB, utilizando las redes sociales como Facebook, Instagram, Omegle, WhatsApp, entre otras. 
y someten a las víctimas. Y para los casos de esclavitud doméstica y sexual simultánea estipular agravantes por doble explotación de las mujeres.

Con la adopción de la Ley contra la trata de personas en 2012, por primera se definieron conceptos básicos, entre otras regulaciones, incluyendo la tipificación del delito en el artículo 52. La entrada en vigencia del nuevo código penal en 2020 derogó la tipificación de la ley especial, pero conservó las definiciones y demás disposiciones legales. En relación a los elementos del delito, ambas legislaciones integran los cinco verbos rectores del Protocolo de Palermo. La ley contra la trata amplió el marco de protección agregando la retención y la entrega, pero el código penal derogó este avance. Los medios eran considerados como agravantes del delito ${ }^{39}$ en la ley especial y no se adecuaban con el Protocolo de Palermo. Con el nuevo código penal, los medios pasaron a ser elementos de la tipificación, aunque no se ajustan totalmente a los estándares internacionales ya que el legislador utilizó términos sinónimos como la violencia, la intimidación, el abuso de una situación de superioridad o necesidad, armonizando solamente el engaño y la entrega o recepción de

39 Las penas anteriores aumentara en un medio (1/2), en los casos siguientes: 1) Cuando la víctima sea menor de dieciocho (18) años de edad; 2) Cuando el autor sea cónyuge, conviviente o pariente de la víctima hasta el tercer grado de consanguinidad o segundo de afinidad; 3) Cuando el sujeto activo haga uso de fuerza, intimidación, engaño, promesa de trabajo o le suministre drogas o alcohol a la víctima; 4) Cuando el sujeto activo se aprovecha de su negocio, oficio, profesión o función que desempeña; 5) Cuando el sujeto activo se aprovecha de la relación de confianza con las personas que tienen autoridad sobre la víctima o hace pagos, préstamos o concesiones para obtener su consentimiento; 6) Cuando el hecho punible fuese cometido por un grupo delictivo integrado por tres (3) o más miembros; y, 7) Cuando la víctima en razón del abuso al que es sometida, queda en estado de discapacidad o contrae una enfermedad que amenace su vida. pagos o beneficios y dejando por fuera la amenaza, el uso de la fuerza u otras formas de coacción, el rapto, el fraude, el abuso de poder y de una situación de vulnerabilidad. Al no existir criterios unánimes de los términos sinónimos integrados en Honduras, los operadores de justicia no cuentan con referencias nacionales para perseguir y sancionar la trata de personas, incumpliendo las obligaciones internacionales.

Respecto a los fines de explotación del Protocolo de Palermo relacionados con la explotación doméstica y sexual de las mujeres, la ley especial incluyó la servidumbre, esclavitud o sus prácticas análogas, trabajos o servicios forzosos y la explotación sexual comercial, extendiendo la protección contra el matrimonio forzado o servil. El código penal conservó la mayoría de modalidades, adicionó la unión de hecho servil o forzada y reformó la modalidad de explotación sexual comercial sustituyendo el último término por "forzada". Ninguna de las dos legislaciones incluyó la prostitución ajena como modalidad de explotación definida a nivel internacional como "la obtención ilícita de beneficios financieros $u$ otro tipo de beneficios materiales mediante la prostitución de otra persona”. (UNODC, 2010.a) En cambio, la ley especial define la explotación sexual comercial como "la utilización de personas en actividades con fines sexuales donde existe un pago o promesa de pago para la víctima o para un tercero que comercia con ella", dejando por fuera cualquier otra forma de explotación sexual que otorgue otro tipo de beneficios a las víctimas (ropa, celulares, accesorios, viajes, etc.) o a las personas explotadoras (uso de la víctima como moneda de pago por actos de corrupción, entre otros). Esa definición quedó inaplicable con el nuevo código penal, pues en su lugar se prevé la explotación sexual forzada. 
Y de acuerdo con la cláusula del consentimiento de la reforma penal de 2020, las víctimas adultas sí pueden consentir a su propia explotación, haciendo la diferencia entre víctimas adultas y menores de edad. Con estas reformas se estaría naturalizando y tolerando la explotación de mujeres al hacer la diferencia entre la explotación sexual "voluntaria” y la ejercida a través del uso de la fuerza u otras formas de coacción, excluyendo la posibilidad de analizar con enfoque de género el uso del engaño, fraude (como falsos noviazgos, amistades o relaciones sentimentales), concesión de pagos o bien en relación al abuso de una situación de vulnerabilidad de la víctima (género, edad, situación de pobreza, baja escolaridad, necesidades básicas insatisfechas, exclusión, relaciones de poder, etc.) (UNODC, 2013) incumpliendo así las obligaciones convencionales de la CADH, CEDAW y la Convención Belem do Pará de sancionar todas las formas de trata o explotación de mujeres.

Para la explotación doméstica en ambas regulaciones se incluye la servidumbre entendida como el "estado de dependencia o sometimiento de la voluntad en el que la persona victimaria por cualquier medio induce, obliga o condiciona a la persona víctima de trata de personas a realizar actos, trabajos o prestar servicios”, la esclavitud o prácticas análogas como "el estado o condición de un individuo sobre el cual se ejercitan los atributos del derecho de propiedad o algunos de ellos" y los trabajos o servicios forzados como "todo trabajo o servicio exigido a una persona bajo la amenaza de un daño o el deber de pago de una deuda espuria”. Con el código penal se prevé por primera vez el delito autónomo de explotación en condiciones de esclavitud o servidumbre sancionando a quien ejerza sobre otra persona un poder de disposición o control y le imponga o mantenga en estado de sometimiento continuado, obligándola a realizar actos, trabajos o a prestar servicios dentro o fuera del país. Esa reducción a la condición de esclavo o de siervo ocurre cuando la situación de sometimiento se logra a través de la violencia, intimidación, engaño o abuso de una situación de superioridad o necesidad de la víctima. Aunque los medios del delito autónomo no se armonizan con el Protocolo de Palermo, de forma general la sanción contra la trata de personas en estas tres modalidades y el delito de esclavitud o servidumbre se adecúa a los estándares internacionales de la C1926, la C1956, el PIDCP, el C29 y el C105, al prever la sanción de los patronos o las patronas que violen gravemente los derechos laborales $\mathrm{y}$ exploten a las trabajadoras domésticas.

La doble explotación de mujeres se sanciona en ambas legislaciones bajo la modalidad de matrimonio forzado o servil, y fue extendida a la unión de hecho forzada o servil en la reforma penal de 2020. Según las definiciones de la ley especial aún vigente, esta modalidad "se produce cuando una persona contrae matrimonio bajo engaño y es sometida a servidumbre sexual y/o laboral". Aunque se aplicó un enfoque de género, la protección contra la doble explotación se limita a estos casos y no se prevé ninguna agravante al respecto en otros contextos de explotación sexual o doméstica.

Las sanciones previstas para estos delitos son aplicables a las personas naturales explotadoras, conocidas como "tratantes". La ley especial no preveía ningún tipo de sanción para las personas jurídicas, pero el nuevo código penal sí las castiga con su disolución o multas que pueden ser acompañadas de: 1) Suspensión de las actividades específicas en las que se produjo el delito; 2) Clausura de locales o establecimientos donde se produjo el delito; 3) Inhabilitación para obtener beneficios e incentivos fiscales 
o de seguridad social y subvenciones/ayudas públicas o contratación con el sector público. Lastimosamente, estas últimas sanciones tienen plazos específicos que van entre cinco a quince años.

Sobre la sanción del clientelismo bajo un enfoque de género prevista en el Protocolo de Palermo, CADH, CEDAW y la Convención Belem do Pará, se observa que el legislador hondureño sigue tolerando, protegiendo o invisibilizando al consumidor de la explotación sexual, pues ni la ley especial ni el código penal prevén la sanción de estos cómplices naturalizando la cosificación, violencia y discriminación de las mujeres.

Finalmente, la ley especial contempla como norma, aún vigente, la no punibilidad de las víctimas por la comisión de delitos o faltas ligadas a su explotación previniendo la criminalización de éstas, así como un marco legal de reparación del daño, el cual hasta la fecha continúa siendo inefectivo ya que nunca se ha reparado a ninguna víctima de trata de personas en Honduras. (CICESCT, 2020) La legislación penal vigente en Honduras para sancionar la explotación sexual y doméstica de las mujeres integra parcialmente los estándares internacionales desarrollados y el enfoque de género. No obstante, del análisis jurídico se desprende que el ordenamiento jurídico hondureño no protege efectivamente a las mujeres del siglo XXI contra la esclavitud moderna, particularmente contra la explotación sexual.

\section{CONCLUSIONES}

- Durante la época colonial se esclavizaron a las poblaciones indígenas y africanas, sentando como base la desigualdad social contemporánea en las Américas. Las mujeres fueron esclavas de una doble explotación: doméstica y sexual. Aunque la esclavitud fue formalmente abolida con la independencia centroamericana, las mujeres seguían y siguen siendo esclavizadas debido a que este fenómeno se ha visto naturalizado con base en prejuicios y estereotipos culturales de género.

- A pesar de los avances internacionales contra la esclavitud contenidos en la C1926, C1956, C29 y C105 de la OIT y el progresivo reconocimiento de derechos de las mujeres, la evolución de la legislación hondureña no los integraba completamente. El análisis cualitativo de las disposiciones constitucionales y penales con aplicación del enfoque de género interseccional y a la luz de la CADH, CEDAW, Convención Belem do Pará y Protocolo de Palermo evidencia que ninguna ley penal adoptada antes del nuevo milenio cumplía a cabalidad con los estándares internacionales de protección contra la esclavitud, la servidumbre, el trabajo forzoso, la prostitución ajena o la explotación sexual.

- En el siglo XXI, la ley contra la trata de personas y el código penal de 2020 integran parcialmente dichos estándares, pero se continúa protegiendo al clientelismo de la explotación sexual, naturalizando la "cosificación" del cuerpo de las mujeres. No se incluyen agravantes por la doble explotación de las mujeres en el ámbito doméstico y sexual, perpetuando la violencia contra ellas. Por tanto, las futuras reformas penales deben estar encaminadas a incluir estos avances para garantizar una protección adecuada a las mujeres. 


\section{AGRADECIMIENTOS}

Al Instituto de Investigación Jurídica por considerar esta contribución para la Revista de Derecho. Y al abogado Luis Ovidio Chinchilla Fuentes por su valioso aporte en la revisión de la presente investigación.

\section{BIBLIOGRAFÍA}

- $\quad$ Bandé Donaire, I.; Zelaya Ocho, M. y Figueroa Escobar, H. (2019). DEMOMUJER. Trabajo doméstico remunerado en el Distrito Central 2018-2019, Volumen 9. Tegucigalpa: Universidad Nacional Autónoma de Honduras, Facultad de Ciencias Sociales, Maestría en Demografía y Desarrollo.

- Barahona, M. (1995). Honduras: El Estado fragmentado (1839-1876). En Taracena, A., \& Piel, J. Identidades nacionales y Estado moderno en Centroamérica. México: Centro de estudios mexicanos y centroamericanos.

- Barahona, M. (2004). El silencio quedó atrás. Testimonios de la huelga bananera de 1954. Tegucigalpa: Guaymuras.

- Bruna, J. (2021, 26 de mayo). La sororidad como pacto: "El valor de la empatía ante el abuso patriarcal debería estar en el ADN de todas las mujeres". El mostrador.

- CICESCT (2018). Informe anual de acciones contra la explotación sexual comercial y trata de personas en Honduras. Tegucigalpa, Honduras.
- CICESCT (2020). Informe nacional en materia de prevención, atención a víctimas y persecución a los delitos de trata de personas y explotación sexual. Tegucigalpa, Honduras.

- Chirix García, E.D. (2019). Estudio sobre racismo, discriminación y brechas de desigualdad en Guatemala. México: CEPAL, Naciones Unidas.

- Cumes, A.E. (2012). Mujeres indígenas, patriarcado, colonialismo: un desafió a la segregación comprensiva de las formas de dominio. Anuario Hojas de Warmi, N 17 . Editum, Universidad de Murcia, España.

- De Oyuela, L. (2001). Mujer, familia y sociedad: una aproximación histórica. Tegucigalpa: Guaymuras.

- Gómez Yepes, T. et al. (2019). Feminismo y activismo de mujeres: sintesis histórica $y$ definiciones conceptuales. Revista Calidad de vida y salud, volumen $12, \mathrm{~N}^{\circ} 1$, pp. $48-61$.

- Guisasola Lerma, C. (2019). Formas contemporáneas de esclavitud y trata de seres humanos: una perspectiva de género. Estudios penales y criminológicos, volumen XXXIX, pp. $175-215$.

- Gulnara Shahinian (2010). Informe de la Relatora Especial sobre las formas contemporáneas de esclavitud, incluidas sus causas y consecuencias, Asamblea General de las Naciones Unidas, A/HRC/15/20.

- Henao, M. I. (2012). Manual de abordaje, orientación y asistencia a víctimas de trata de personas con enfoque de género y de derechos. Organización Internacional para las Migraciones (OIM). Bogotá: CODICE. 
- Kadish, D. Y. \& Massardier-Kenney, F. (1994). Translating Slavery: Gender and Race in French Women's Writing, 1783 - 1823. Kent, Ohio and London, England: Kent State University Press.

- Mandel Katz, C. (2016). Emilia Prieto: una precursora de la disidencia de identidad respecto del discurso cultural dominante en Costa Rica, entre 1925-1945. En Herrera Mena, S. A. et al. Historia de las desigualdades sociales en América Central. Una visión interdisciplinaria siglos XVIII-XXI (pp.465 483). San José: Ronny J. Viales Hurtado y David Díaz Arias Editores.

- Mariñas Otero, L. (2008). Honduras. Tegucigalpa: Cultura.

- Montanaro Mena, A.M. (2017). Una mirada al feminismo decolonial en América Latina. Madrid: Dykinson.

- O’Neill, Sally (2019). En búsqueda de la justicia. Trata de personas para la explotación sexual en Honduras.

- Palumbo, L. (2018, 12 de julio). La necesidad de un enfoque de género para abordar la explotación y la trata de personas. openDemocracy.

- Ramírez Rivas, K. E. (2020, 19 de noviembre). Alba Alonzo de Quesada, un legado para las mujeres y el país. Presencia Universitaria.

- Revista del Archivo y Biblioteca Nacionales (s.f.). En Honduras habían esclavos aún después de la independencia. Blog: Honduras Is Great. Recuperado en https:// hondurasisgreat.org/esclavos-honduras/
- Rodríguez,M.(2014).Formas contemporáneas de esclavitud y tortura. Una mirada desde las vidas de las mujeres. En Maris Martínez, S. et al. Género, esclavitud y tortura. A 200 años de la Asamblea del año XIII (pp. 81 - 100). Buenos Aires: Jusbaires.

- Rodríguez, E. (2017, 25 de enero). La UNAH tiene rostro de mujer. Presencia Universitaria.

- Saénz Carbonell, J. F. (2012). Los ordenamientos normativos indígenas de Honduras. Revista Judicial, N 105 (pp.35 78). Recuperado de https://www.corteidh. or.cr/tablas/r29224.pdf

- Shahinian, G. (2010). Informe de la Relatora Especial sobre las formas contemporáneas de esclavitud, incluidas sus causas y consecuencias, A/HRC/15/20, Consejo de Derechos Humanos, Asamblea General de las Naciones Unidas.

- Thill, M. y Giménez Armentia, P. (2016). El enfoque de género: Un requisito necesario para el abordaje de la trata de seres humanos con fines de explotación sexual. Revista Europea de Derechos Fundamentales, primer semestre, $\mathrm{N}^{\circ} 27$, pp. 439 - 459.

- Torres Calderón, M (s.f.). La lucha popular más prolongada desde los 69 días de la huelga bananera 70 y más días de resistencia contra el golpe y la sumisión. El Inventario.

- Túnez, F. (2014). Trata y prostitución, esclavitud del presente. En Maris Martínez, S. et al. Género, esclavitud y tortura. A 200 años de la Asamblea del año XIII (pp. 51 55). Buenos Aires: Jusbaires. 
- UNODC (2010.a). Ley modelo contra la trata de personas. Nueva York: UN.GIFT - Global Iniciative to Fight Human Trafficking.

- UNODC (2010.b). Manual sobre la lucha contra la trata de personas para profesionales de la justicia penal.

- UNODC (2013). Manual sobre el Abuso de una situación de vulnerabilidad y otros "medios" en el contexto de la definición trata de personas.

- Valladares, O.A. (2009). El amancebamiento como delito sexual en el siglo XVII en la Alcaldía Mayor de Tegucigalpa. Tegucigalpa: Cultura.

- Villalibre Fernández, V. (2009). Esclavitud ¿moderna? Reflexiones desde el derecho internacional de los derechos humanos. Recuperado de http://www.gencat.cat/drep/ ipau/sumaris/esclavitud.pdf

- Villalpando, W. (2014). La esclavitud, el crimen que nunca desapareció. La trata de personas en la legislación internacional. En Maris Martínez, S. et al. Género, esclavitud y tortura. A 200 años de la Asamblea del año XIII (pp. 31 - 47). Buenos Aires: Jusbaires.

\section{Referencias institucionales:}

- Asamblea Nacional Constituyente (1824). Constitución de la República Federal de Centroamérica. Centroamérica. 22/11/1824.

- Asamblea Nacional Constituyente (1825). Constitución del Estado. Honduras. $11 / 12 / 1825$.
- Asamblea Constituyente (1839). Constitución Política del Estado. Honduras. 11/01/1839.

- Asamblea Constituyente (1848). Constitución Política del Estado. Honduras. 05/02/1848.

- Asamblea Constituyente (1865). Constitución Política de la República. Honduras. 29/09/1865.

- Asamblea Constituyente (1873). Constitución Política de la República. Honduras. 25/12/1873.

- Asamblea Nacional Constituyente (1880). Constitución de la República. Honduras. 1/12/ 1880.

- Asamblea Nacional Constituyente (1895). Decreto $\mathrm{N}^{\circ} 30$. Código penal. Honduras.

- Asamblea Nacional Constituyente (1906). Decreto $\mathrm{N}^{\circ} 76$. Código penal militar. Honduras.

- Comisión Codificadora y Soto, M.A. (1880). Código penal. Honduras.

- Congreso Nacional (1984). Decreto $N^{\circ} 144-$ 83. Código penal. Honduras.

- Congreso Nacional (2020). Decreto 1302017. Código penal. Honduras.

- Congreso Nacional (2012). Decreto 59-2012. Ley contra la trata de personas. Honduras. 
Referencias internacionales (instrumentos y jurisprudencia):

- Asamblea General de las Naciones Unidas (1948). Declaración Universal de Derechos Humanos.

- Asamblea General de las Naciones Unidas (1966). Pacto internacional de derechos civiles y políticos.

- Asamblea General de las Naciones Unidas (1979). Convención sobre la eliminación de todas las formas de discriminación contra las mujeres.

- Consejo Económico y Social (1956). Convención suplementaria sobre la abolición de la esclavitud, la trata de esclavos y las instituciones y prácticas análogas a la esclavitud.

- Corte IDH (2016). Caso trabajadores de la Hacienda Brasil Verde vs. Brasil. Excepciones preliminares, fondo, reparaciones y costas. Sentencia de 20 octubre de 2016.

- Organización de los Estados Americanos (1969). Convención Americana sobre Derechos Humanos.

- Organización de los Estados Americanos (1994). Convención Interamericana para prevenir, sancionar y erradicar la violencia contra la mujer "Convención Belem do Pará".

- OIT (1930). Convenio sobre el trabajo forzoso (C29).

- OIT (1957). Convenio sobre la abolición del trabajo forzoso (C105).
- Sociedad de las Naciones (1926). Convención sobre Esclavitud.

- TEDH (2005). Caso Siliadin v. Francia. Demanda $N^{\circ} 73376 / 01$. Sentencia del 26 de julio 2005. 